\title{
Torque Power and Angle Movement of the Shoulder Joint in Archery
}

ISSN: 2637-7748

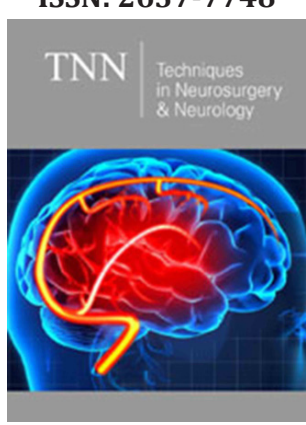

*Corresponding author: Andrzej Kępczyński, Klinika Ruchu Warsaw, Poland

Submission: 睯 February 24, 2021

Published: 制April 21, 2021

Volume 4 - Issue 2

How to cite this article: Andrzej Kepczyński, Michalina Błażkiewicz. Torque Power and Angle Movement of the Shoulder Joint in Archery. Tech Neurosurg Neurol. 4(2). TNN. 000582. 2021.

DOI: $10.31031 /$ TNN.2021.04.000582

Copyright@ Andrzej Kępczyński, This article is distributed under the terms of the Creative Commons Attribution 4.0 International License, which permits unrestricted use and redistribution provided that the original author and source are credited.

\author{
Andrzej Kępczyński1* and Michalina Błažkiewicz² \\ ${ }^{1}$ Klinika Ruchu Warsaw, Poland \\ ${ }^{2}$ University of Physical Education Warsaw, Poland
}

\section{Introduction}

According to the International Archery Federation (FITA), the shoulder problem in archery is the most common disease [1]. As per the FITA Medical Committee, between 19932001 , the shoulder joint was the most frequently damaged joint (47\%). They were chronic lesions as the result of overstrain, not injures. So, the following questions are: 1 . How is the movement of the shoulder during the arch lift? 2. What torque power are generated during this movement? 3. Can this data help answer the question of how shoulder dysfunction arises in archery?

\section{Material and Method}

In our work, we examined two groups: professional archers (Polish national team) and a control group-people holding a professional bow in their hands for the first time. Both groups consisted of 15 people $(n=15)$. Polish team group: average age $23.47 \pm 9.25$, body weight $(\mathrm{kg})$ $73.07 \pm 16.18$, body height $176 \pm 9.18$, training period (years) $11.07 \pm 7.92$. The control group: average age $27.75 \pm 9.25$, body weight $(\mathrm{kg}) 73.27 \pm 16.72$, body height $176 \pm 13.45$, training period (years) 0 (Table 1). The markers were placed on the body of examined people. The marker placement was based on the Plug-in-Gait Marker Placement scheme [2]. The examined people were to raise the bow to the shooting position, draw the string, then loosen the string and lower the bow. The markers movements were recorded by the VICON movement recording system. The study took place at the Central Research Laboratory of the University of Physical Education in Warsaw. The VICON system uses retro reflective markers placed on the body of the examined person. Their movement is recorded by infrared cameras. Thanks to video recording, we got kinematic (angular) parameters and kinetic parameters (torque power) of both studied groups. In both measurements we focused on the results for the following movements: flexion/extension, external/internal rotation, abduction/adduction.

Table 1:

\begin{tabular}{|c|c|c|c|c|}
\hline & Age & Body Weight & Body Height & Training Period(Years) \\
\hline Polish national team & $23.47 \pm 9.25$ & $73,07 \pm 16,18$ & $176 \pm 9,18$ & $11,07 \pm 7,92$ \\
\hline Control group & $27,75 \pm 9,25$ & $73,27 \pm 16,72$ & $176 \pm 13,45$ & 0 \\
\hline
\end{tabular}

Result

Professional archers, in order to make the gesture of raising the bow and drawing the string, made a bending/extending movement involving moments of force adequately $0.005 /-0.073 \mathrm{Nmkg}$. The moments of the abduction/adduction forces were proportionally $0.092 / 0.027 \mathrm{Nmkg}$. On the other hand, the moments of the internal/external rotation forces were $-0.008 /-0.035 \mathrm{Nmkg}$. In the group of amateurs, the torque power in the flexion/ extension movements were $0.003 /-0.024 \mathrm{Nmkg}$. Abduction/adduction required torque power of $0.085 / 0.051 \mathrm{Nmkg}$. Internal/external rotations $-0.016 /-0.029 \mathrm{Nmkg}$. The analysis of the muscular torque showed that among archers the flexion movement did not require the involvement of large torque power. We even noted a reduction in abduction force moment during the angular change. However, in the rotations, we recorded a systematic linear increase in the torque of muscle power. In the control group, we observed huge individual 
disproportions and large fluctuations in the torque power, both in flexion and abduction, as well which increased quite chaotically from -0.02 to $0 \mathrm{Nmkg}$ in 200 seconds (muscle shivering) and continued to increase again. However, the rotations did not show a proportionally large increase in the torque power acting on the shoulder joint [Figures 1-4]. The kinematic parameters in the group of archers were as follows: Flexion/extension - the movement started at about $50^{\circ}$ flexion, then increased to $70^{\circ}$ flexion for the first 20 seconds and gradually decreased until it reached $0^{\circ}$ and extends at 250 second. At the 300 second, the shoulder joint was positioned at about $10^{\circ}$ extension. Abduction/adduction - a very linear abduction, till 170 seconds. Staying in one position for up to the 250 second (time to take a shot) and then up to 300 second, increasing the abduction to $90^{\circ}$. Internal/external rotation from the 100 second up to the 250 second fast, gradual increase in external rotation from $45^{\circ}$ internal rotation to $100^{\circ}$ external rotation during the firing phase, maintaining this position (shot) and reducing external rotation to $90^{\circ}$ until the end of the movement in the 300 seconds - bow lowering. In the control group: flexion/extension movement, similarly to professionals, started with $50^{\circ}$ flexion, then for 100 second the flexion increased to $70^{\circ}$ in the 100 second and further began to decrease until it reached $40^{\circ}$ in the 300 second. The Control group abduction/ adduction movement started with abduction to $90^{\circ}$ to the 20 second and holding this position till the 200 second, in which a 10 -step abduction appeared lasted 10 seconds (firing a shot) and a return to unchanged until the 300 second. It should be emphasized that in the group of archers there were slight differences in kinetic and angular parameters between the individual examined people. In the control group, however, there were very large individual differences.

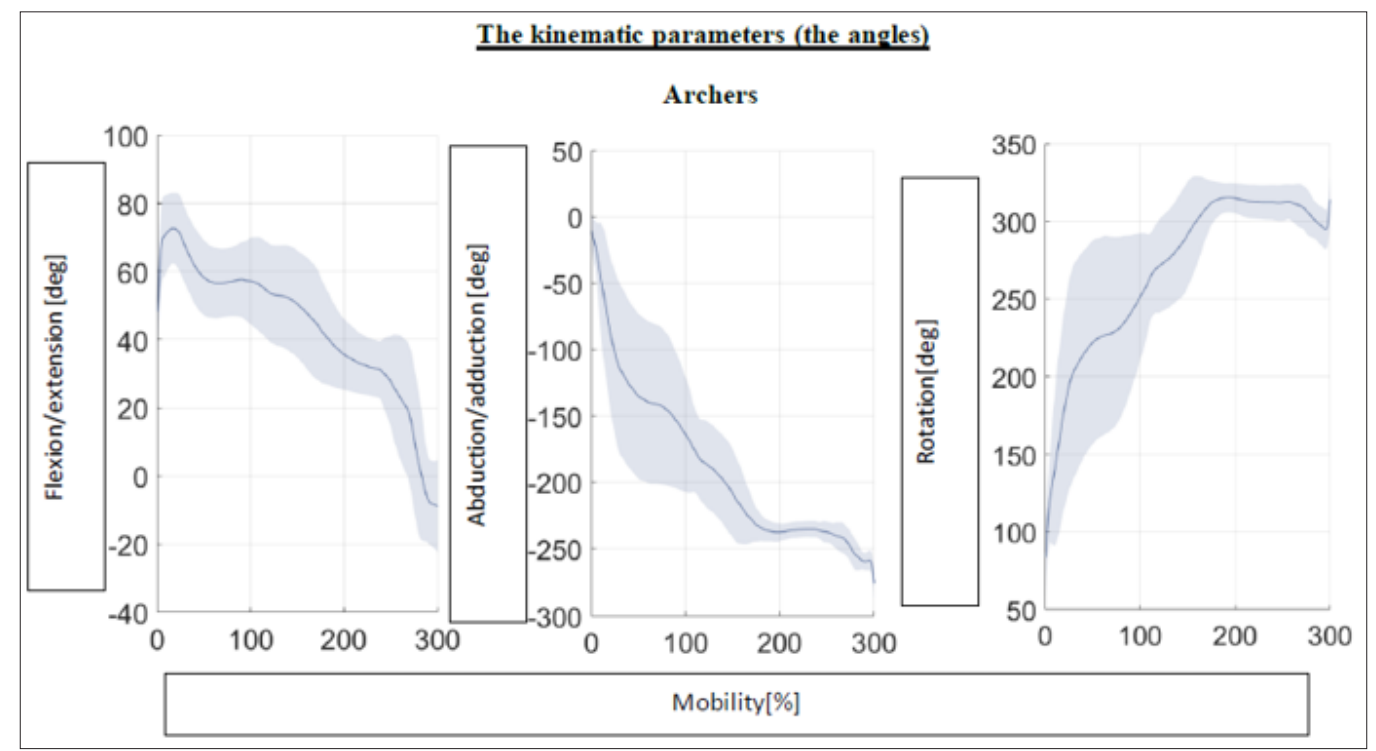

Figure 1:

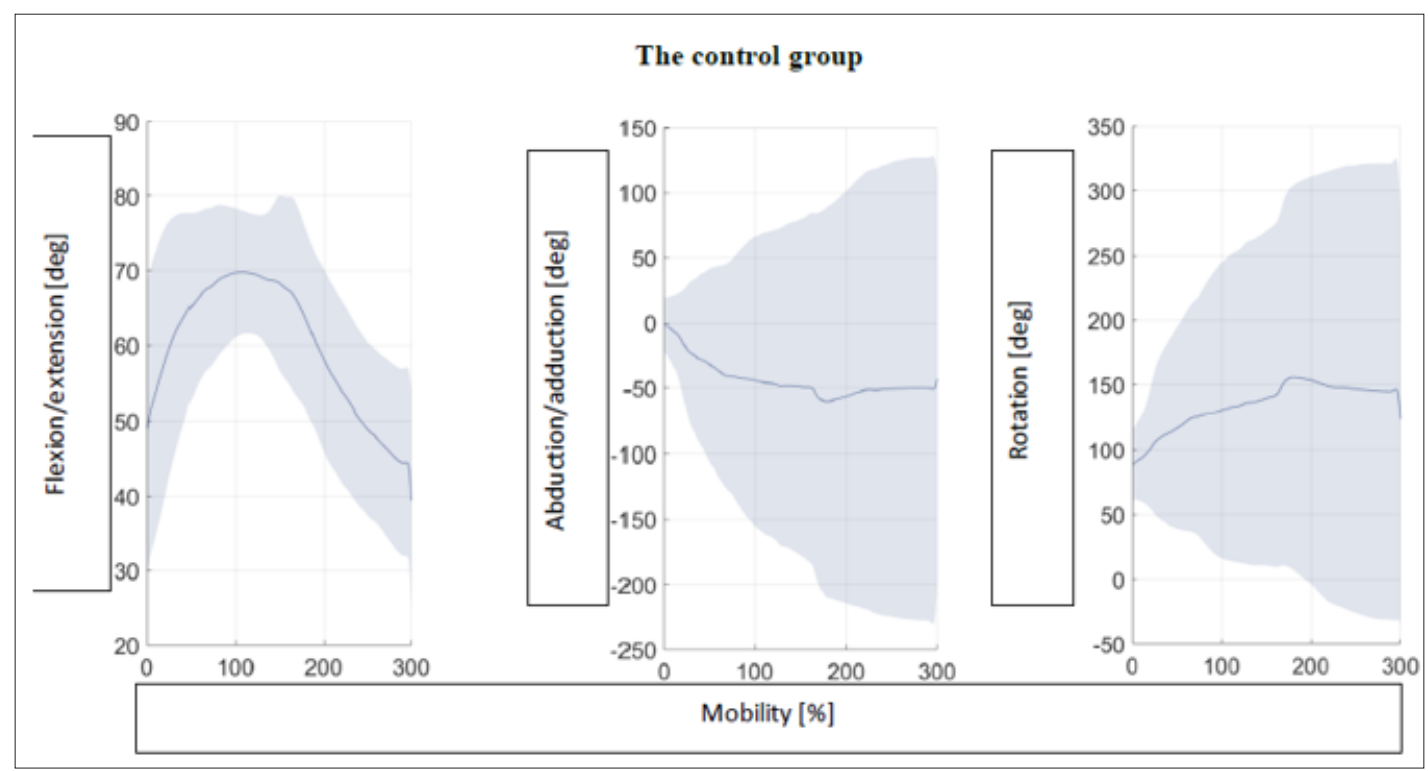

Figure 2: 


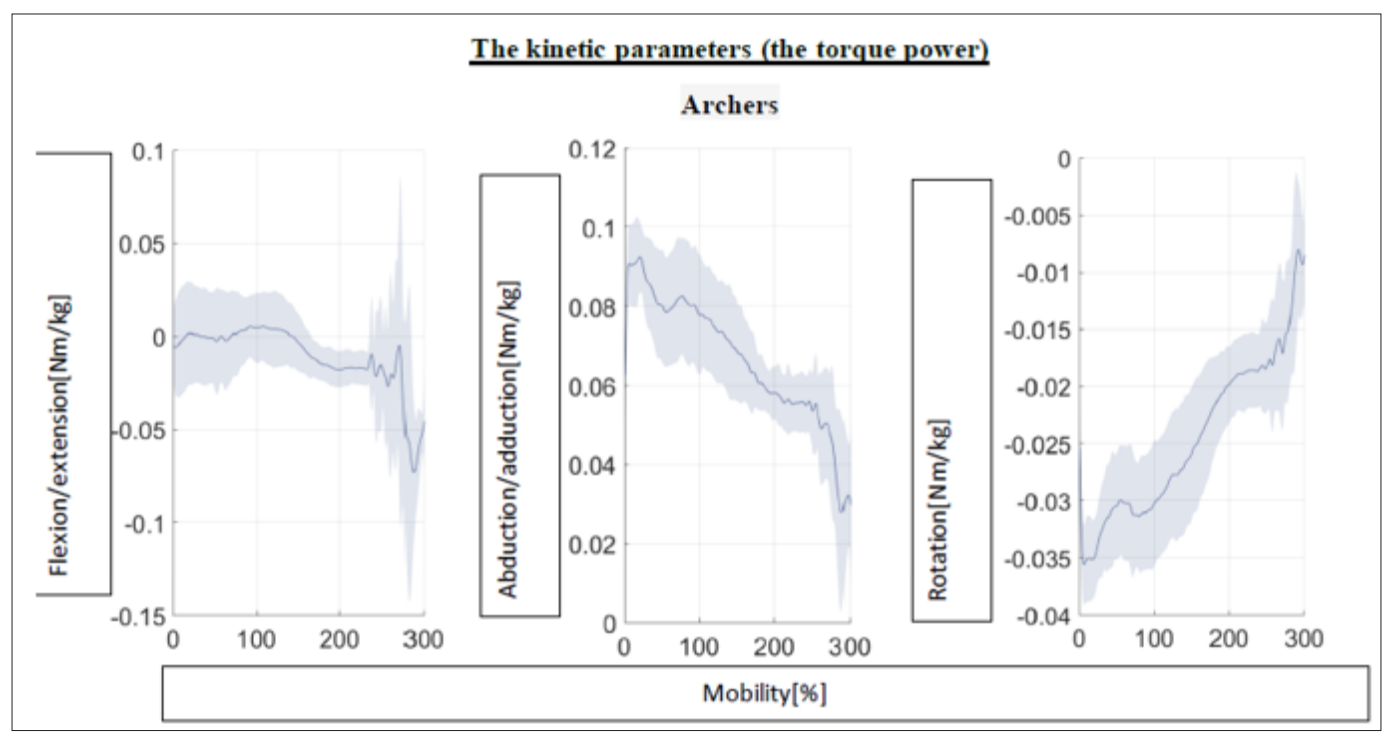

Figure 3:

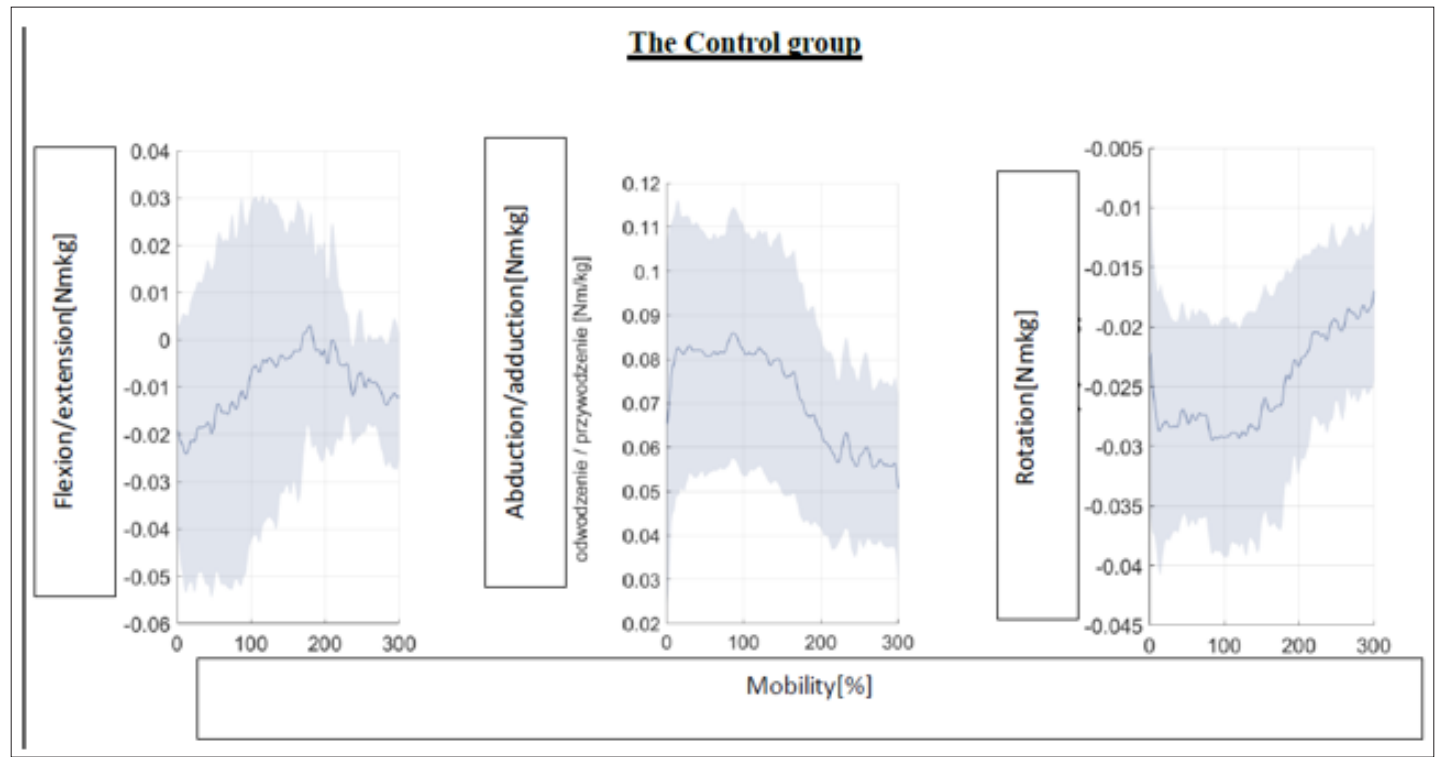

Figure 4:

\section{Discussion}

Monitoring of the action of the torque power acting on the shoulder joint during the movement of raising the bow to the shooting position showed large quantitative and qualitative differences between the group of professional archers and the control group. This seemingly obvious conclusion means that we know what is changed while training archery and at the same time what causes the growth of the effectiveness of this sport, i.e., hitting the target. At the same time, on the basis of comparative studies, we can draw conclusions about the causes of morphological changes and next as a result damages of the structures of the shoulder joint. The bow-raising gesture in the control group was performed by turning the body towards the raised bow. A group of archers made this move by abduction in the frontal plane. This difference caused a high rotational activity in the shoulder joint of the archers. The control group, on average, did not activate the shoulder rotators, and the movement was done more by flexion than rotation. From the point of view of the sports benefit, the archers used smaller torque, which resulted in less muscle tremors and resulted in greater accuracy if we were to shoot. However, the movement that was performed by amateurs from the control group gave the less strain on the shoulder joint. It is related to the Codman phenomenon and the biomechanics of the shoulder joint [3]. The movement performed by archers used the locking of joints, which is described in the literature as one of the most important points of the shooting technique [4]. On the one hand, interlocking causes a reduction in muscle activity, but on the other hand, it can cause impingement syndromes in the shoulder joint and damage the joint structures. This is the answer why shoulder damage is one of the main ailments among high-performance archers [5]. 


\section{Conclusion}

Damages of the shoulder joint in archery is the reason of the inappropriate shooting technique as well as an inadequate selected bow. While the technology of manufacturing equipment is developing very quickly due to new materials and the demand for modern equipment, the treatment of injuries in this sport is slightly behind due to its relatively low popularity in the world. This work finds potential causes of a shoulder joint dysfunction in archers and should become the basis for the creation of a specific exercise program ensuring the prevention and treatment of shoulder joint syndrome in archers. Such an exercise program should be based on the cooperation of players, coaches and physiotherapists.

\section{References}

1. Al MH (2008) Common injuries area among archers.

2. Mohd Azrul Hisham (2014) Biomechanics measurements in archery. Journal of Mechanical Engineering and Sciences 6: 762-771.

3. VICON plug- in gait marker placement.

4. Kapandji I (1975) The physiology of the joints. Postgraduate Medical Journal.

5. Ertan H (2009) Muscular activation patterns of the bow arm in recurve archery. J Sci Med Sport 12(3): 357-360.

For possible submissions Click below: 